\title{
Dyeing Performance of Yellow Pigment from Ginkgo Biloba Leaves on the Cannabis/ Mulberry Fiber/Wool fiber Blended Yarn
}

\author{
Linlong ZHANG, Lei ZHAO, Li WEI \\ ${ }^{1}$ Yan cheng institute of industry technologe, Yancheng, 224005, china \\ azll8018997@126.com, ${ }^{\mathrm{b}}$ zhaolei7365@163.com, ${ }^{\mathrm{c} w 1 x z y c @ 163 . c o m}$
}

Key words: Ginkgo Biloba Leave; Mordant dyeing; absorbance; Color depth value; color fastness Abstract: Using natural dye Ginkgo leaves as raw materials, the dye liquid was extracted by microwave method, water bath method and ultrasonic extraction method, and the suck photometric of this three extraction liquid were tested. The 25 tex cannabis/mulberry fiber/wool $60 / 20 / 20$ blended yarn was dyed by the extracted liquid. The four factors of $\mathrm{pH}$ value, dyeing temperature, mordant dosage, and penetration agent dosage were used to analyze dyeing effect. On the basis of the above four factors, three level of orthogonal experiment was designed to dye the blended yarn, the color fastness of the orthogonal samples were tested. The results showed that the absorbance of the pigment extracted by microwave-assisted extraction method was the highest, and the best dying techniques as: osmotic dosage of $1.5 \mathrm{ml}$, and mordant $15 \mathrm{ml}$ dye $\mathrm{pH} 10$, dyeing temperature of 60 degrees centigrade. The color fastness and wet fastness cannabis/mulberry fiber blended yarn after dyeing achieve level 3 or above.

\section{Introduction}

Since entering the new century, with the increase of people's living standards and the pursuing material enjoyment, the changes in the environment attract more and more attention. Textile, printing and dyeing industry in the production process emits large amounts of sewage, causing serious damage to the environment in which people live, and there is certainly aware of the industrial production of synthetic dyes which have some toxic effects on people's health; development of natural plant dye extraction process does not produce large amounts of sewage and no pollution to the environment, so using it to dye textiles meets the requirements of ecological textiles[1-2].

Extract of dry yellow Ginkgo leaves contain high content of pharmaceutical composition-flavonoids compounds, which up to a maximum of 5.91\%; The ginkgo biloba leaf flavonoids is acid and of polycyclic polyphenolic,and it contain high amounts of phenolic hydroxyl groups,also it is harmless, innocuous, healthy to the human body. Current research focuses on the extraction of active substance from the Ginkgo leaf, Liu Wenjing of Dalian Polytechnology University research on Ginkgo leaf natural dyes dye mordant dyeing process of cotton fabrics, Lu Sheng from Eastern Liaoning University, who studied dyeing performance of natural dyes-ginkgo biloba leaves on tussah silk fabric,but there are no reports about natural dyes-ginkgo leaves which are used for dyeing other cellulose fabric yet.Cannabis/mulberry fiber/wool blend yarn is a new product from Jiangsu Yueda Textile Group, we analyze and research on the dyeing performance, dyeing process and dyeing results of natural dye-ginkgo biloba on cannabis/mulberry fiber/wool blend yarn, so the dyeing process has been optimized[3-5]. 


\section{Experiment}

\section{Materials and Instruments}

Ingredients: Ginkgo biloba, 25tex cannabis/mulberry fiber/wool 60/20/20 blend yarn, 400 mesh strainer;

Reagents: sodium hydroxide, aluminum sulfate, acetic acid, ethanol, pure for analysis;JFC penetrant $(20 \mathrm{~g} / \mathrm{L})$;

Instrument: pHB-8 pH meter, UV-1801 UV-visible spectrophotometer, Datacolor 600 computer colorimeter, CX multi-function high more than 350 mill;PRD-S-01DHT ultrasonic cleaner.

\section{Experimental Procedures}

\section{Extraction of Pigment}

Dry yellow Ginkgo leaf was shattered into powder by the shredder; The ginkgo biloba yellow pigment was extracted by three kinds of method,microwave extraction, water bath extraction, ultrasonic extraction when $\mathrm{pH}$ value is 11 and liquor ratio is 1:60; We can get ginkgo biloba yellow pigment liquid after the filterring. The extraction program is shown in Table.1.

Table.1 Extraction programme of the yellow pigment from ginkgo biloba

\begin{tabular}{cccc}
\hline Program & Extraction method & Time & The amount of alcohol \\
\hline 1 & Microwave microflame & $5 \mathrm{~min}$ & $0 \%$ \\
2 & Microwave microflame & $5 \mathrm{~min}$ & $50 \%$ \\
3 & Microwave microflame & $5 \mathrm{~min}$ & $75 \%$ \\
4 & Microwave microflame & $5 \mathrm{~min}$ & $100 \%$ \\
5 & Water bath method $\left(70^{\circ} \mathrm{C}\right)$ & $2 \mathrm{~h}$ & $0 \%$ \\
6 & Ultrasonic method $\left(50 \%\right.$ power $\left.、 25^{\circ} \mathrm{C}\right)$ & $30 \mathrm{~min}$ & $75 \%$ \\
\hline
\end{tabular}

\section{Measurement of pigment absorbance}

Take $25 \mathrm{~mL}$ extracting pigments liquid from the above six methods and diluted them into 50 $\mathrm{mL}$ with ethanol, we measure absorbance of the solution at $430 \mathrm{~nm}$ wavelength and determine the best program.

\section{Dyeing method and dyeing process}

Table. 2 Orthogonal factors of dyeing process

\begin{tabular}{ccccc}
\hline & \multicolumn{4}{c}{ factor } \\
\cline { 2 - 5 } level & $\mathrm{A}$ & $\mathrm{B}$ & $\mathrm{C}$ & $\mathrm{D}$ \\
& penetration agent dosage & mordant dosage & dying pH value & dying temperature \\
\hline 1 & $1 \mathrm{ml}$ & $10 \mathrm{ml}$ & 8 & $60^{\circ} \mathrm{C}$ \\
2 & $1.5 \mathrm{ml}$ & $15 \mathrm{ml}$ & 9 & $70^{\circ} \mathrm{C}$ \\
3 & $2 \mathrm{ml}$ & $20 \mathrm{ml}$ & 10 & $80^{\circ} \mathrm{C}$ \\
\hline
\end{tabular}

Dilute $5 \mathrm{~g}$ aluminum sulfatealum mordant to $11 \mathrm{using}$ distilled water and use mordant dying method on 25 tex cannabis/mulberry fiber/wool 60/20/20 blended yarn; we extract $5 \mathrm{ml}$ diluted mordant and dilute to $100 \mathrm{ml}$ according to bath of $1: 50$ and temperature of $80^{\circ} \mathrm{C}$, then we into $0.5 \mathrm{~g}$ yarn, constantly mixing yarn; After 30minutes, we take the yarn out and wring it; we use four single factors of $\mathrm{pH}$ value, dyeing temperature, mordant dosage and penetration agent dosage to analyze dyeing effect and combined orthogonal experiment for analysis. Orthogonal experiment programme is shown in Table.2, the dye ratio of 1:60, dyeing process curve is seen in Fig. 1. 


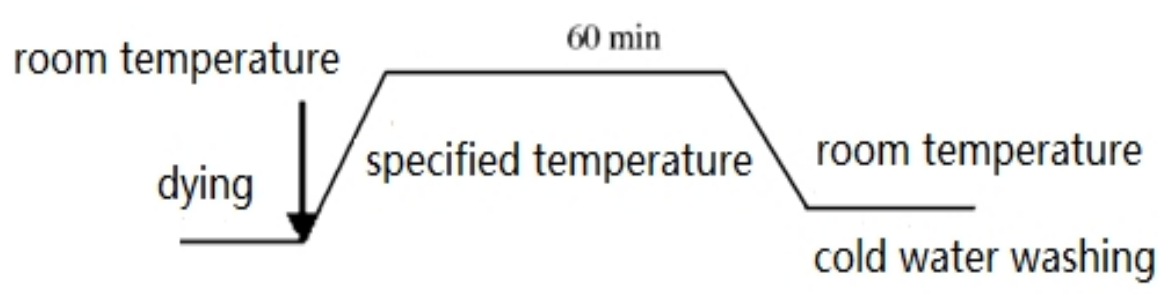

Fig.1 Dyeing process curve

\section{Measurement of color depth value}

Circle the dyeing yarn evenly around the cardboard into a thin layer and place it on the Datacolor 600 PC color measuring instrument. We measure values of K/S, a, b, c * values at the wavelength of maximum absorption. We we get average by measuring 3 points of the sample.

\section{Testing of washing colour fastness to resistance}

Washing colour fastness to resistance of the yarn was tested In accordance with GB/t 3921 . 1-19975 testing method.

\section{Results and analysis}

Effect of different extracting methods on stability of ginkgo biloba leaves pigment Table.3 Effect of different extraction methods on the stability of pigment

\begin{tabular}{ccccccc}
\hline Programme & 1 & 2 & 3 & 4 & 5 & 6 \\
\hline absorbance(A) & 0.572 & 0.632 & 0.654 & 0.658 & 0.453 & 0.345
\end{tabular}

The absorbance of pigment from ginkgo biloba leaves under different extraction is shown in Table.3. From Table.3 we can see that the sucking photometric value of the pigment extracted by microwave method is obviously high than the water bath method and ultrasonic method. During the extraction by microwave method, the sucking photometric value enchance with the increase of the ethanol dosage, but when the ethanol dosage exceed $75 \%$, there is no obvious change about the sucking photometric value of the pigment. This is because microwave can makes some regional of yellow ketone class compounds in ginkgo leaves or some component of ginkgo leaves was heated selectively, so the yellow ketone class compounds separated from matrix or system can enter into ethanol solvent which has small dielectric constant and relatively poor microwave absorbing ability; this also explain that the flavonoid compounds have very good compatibility with ethanol and water and ultrasonic effect is relatively weak, not enough to make an effective separation of flavonoid compounds, so the dying pigmentation of all the experments is extracted by Programme 3.

\section{Analysis of single factor about ginkgo biloba leaves dying on the blended yarn Effect of $\mathrm{pH}$ value on dying}

The K/S value of the cannabis/mulberry fiber/wool blended yarn under different $\mathrm{pH}$ values is shown in Table.4,other dying condition is that penentrating agent dosage of $0.5 \mathrm{ml}$, dyeing temperature of $80^{\circ} \mathrm{C}$, mordant amount of $10 \mathrm{ml}$. From Table. 4 we can see that $\mathrm{K} / \mathrm{S}$ value of the yarn is very small when $\mathrm{pH}$ value is less than $7, \mathrm{~K} / \mathrm{S}$ value of the yarn increase then decrease when $\mathrm{pH}$ value overpass $7 . \mathrm{K} / \mathrm{S}$ value reached maximum at $\mathrm{pH}$ value of 9 , This is because mulberry fiber and cannabis belong to cellulose fiber, large of hydrophilic group on their surface was damaged under acid condition and can't react with large of phenol hydroxy on yellow ketone compounds into chemical key. 
Table.4 Effect of different $\mathrm{pH}$ value on dying

\begin{tabular}{ccccccccc}
\hline $\mathrm{pH}$ & 5 & 6 & 7 & 8 & 9 & 10 & 11 & 12 \\
\hline $\mathrm{K} / \mathrm{S}$ & 1.5347 & 1.6374 & 2.0750 & 2.5012 & 2.5753 & 2.4281 & 2.4238 & 1.9585 \\
\hline
\end{tabular}

\section{Effect of temperature on dying}

Table.5 Effect of different temperature on dying

\begin{tabular}{ccccccc}
\hline temperature & $50^{\circ} \mathrm{C}$ & $60^{\circ} \mathrm{C}$ & $70^{\circ} \mathrm{C}$ & $80^{\circ} \mathrm{C}$ & $90^{\circ} \mathrm{C}$ & $100^{\circ} \mathrm{C}$ \\
\hline K/S value & 2.8759 & 3.0134 & 3.3123 & 2.5753 & 1.8022 & 1.7345 \\
\hline
\end{tabular}

The K/S value of the cannabis/mulberry fiber/wool blended yarn under different temperature is shown in Table.5,other dying condition is that penentrating agent dosage of $0.5 \mathrm{ml}$, mordant amount of $10 \mathrm{ml}$, dyeing $\mathrm{pH}$ value of 9 . From Table.5 we can see that $\mathrm{K} / \mathrm{S}$ value of the yarn increase then decrease with the raise of temperature, $\mathrm{K} / \mathrm{S}$ value reached maximum at temperature of $70^{\circ} \mathrm{C}$. When the temperature is low, the ginkgo biloba yellow pigment can't dye the fabric fastly, The dye uptake is very low because be subject to the dying time. When the temperature is high, the molecules of yellow ketone compounds in ginkgo biloba leaf pigment can't be combined effectively with cellulose fiber.

\section{Effect of mordant dosage on dying}

Table. 6 Effect of different mordant dosage on dying

\begin{tabular}{cccccc}
\hline dosage & $5 \mathrm{ml}$ & $10 \mathrm{ml}$ & $15 \mathrm{ml}$ & $20 \mathrm{ml}$ & $25 \mathrm{ml}$ \\
\hline K/S value & 1.8926 & 3.3123 & 3.3524 & 3.3531 & 3.3559 \\
\hline
\end{tabular}

The K/S value of the cannabis/mulberry fiber/wool blended yarn under different mordant dosage is shown in Table.6,other dying condition is that penentrating agent dosage of $0.5 \mathrm{ml}$, dyeing $\mathrm{pH}$ value of 9 , dying temperature of $70^{\circ} \mathrm{C}$. From Table. 6 we can see that $\mathrm{K} / \mathrm{S}$ value of the yarn increase with the raise of mordant dosage, when the mordant dosage exceeds $15 \mathrm{ml}$, K/S value of the blended yarn leveled off. Because the blended yarn was treated by mordant, the group on the fiber can react with mordant aluminum sulfate to form two-dimensional complexes. After pre-mordant of the blended yarn, the ginkgo biloba which have hydroxyl and ketoand can form complexes with $\mathrm{Al}^{3+}$ of metal ions. As a result, the dye uptake of the ginkgo leaves yellow pigment was enchanced greatly; when the mordant dosage was saturated, the combination of complexes was also stabilized.

\section{Effect of the penentrating agent dosage on dying}

Table.7 Effect of different penentrating agent dosage on dying

\begin{tabular}{cccccc}
\hline dosage & $0.5 \mathrm{ml}$ & $1 \mathrm{ml}$ & $1.5 \mathrm{ml}$ & $2 \mathrm{ml}$ & $2.5 \mathrm{ml}$ \\
\hline $\mathrm{K} / \mathrm{S}$ & 3.3524 & 3.3734 & 3.3765 & 3.3787 & 3.3795 \\
\hline
\end{tabular}

The K/S value of the cannabis/mulberry fiber/wool blended yarn under different penentrating agent dosage is shown in Table.7,other dying condition is that dyeing $\mathrm{pH}$ value of 9 , dying temperature of $70^{\circ} \mathrm{C}$, mordant amount of $0.5 \mathrm{ml}$. From Table. 7 we can see that $\mathrm{K} / \mathrm{S}$ value of the yarn increase greatly when the penentrating agent dosage change from $0.5 \mathrm{ml}$ to $1 \mathrm{ml}$; but if the penentrating agent dosage continue to increase, the increase of the $\mathrm{K} / \mathrm{S}$ value increases reduced obviously. This is because the penentrating agent can reduce the surface tensionof the blended yran, and the ginkgo leaves pigment can beabsorbed on the fiber surface or penetrate into the internal yarn, and produced chemical bond with hydroxy group. 
Orthogonal experimental analysis about ginkgo biloba leave pigment dyed on blend yarn

Table. 8 Analysis of orthogonal experiment

\begin{tabular}{|c|c|c|c|c|c|}
\hline $\begin{array}{c}\text { Serial } \\
\text { number }\end{array}$ & $\begin{array}{c}\text { penentrating agent } \\
\text { dosage } / \mathrm{ml}\end{array}$ & $\begin{array}{c}\text { mordant } \\
\text { dosage } / \mathrm{ml}\end{array}$ & Dying $\mathrm{pH}$ & $\begin{array}{c}\text { Dying } \\
\text { temperature } /{ }^{\circ} \mathrm{C}\end{array}$ & $\mathrm{k} / \mathrm{s}(360 \mathrm{~nm})$ \\
\hline 1 & 1(1) & $1(10)$ & 1(8) & $1(60)$ & 3.0303 \\
\hline 2 & $1(1.5)$ & $2(15)$ & 2(9) & $2(70)$ & 3.1513 \\
\hline 3 & $1(1.5)$ & $3(20)$ & $3(10)$ & $3(80)$ & 3.1443 \\
\hline 4 & $2(1.5)$ & $1(10)$ & $2(9)$ & $2(70)$ & 4.0234 \\
\hline 5 & $2(1.5)$ & $2(15)$ & $3(10)$ & $1(60)$ & 4.2221 \\
\hline 6 & $2(1.5)$ & $3(20)$ & 1(8) & $3(80)$ & 3.0703 \\
\hline 7 & $3(2)$ & $1(10)$ & $3(10)$ & $2(70)$ & 3.0082 \\
\hline 8 & $3(2)$ & $2(15)$ & $1(8)$ & $3(80)$ & 3.5711 \\
\hline 9 & $3(2)$ & $3(20)$ & 2(9) & $1(60)$ & 3.0332 \\
\hline I1 & 9.3329 & 10.0619 & 9.6717 & 10.2856 & \\
\hline $\mathrm{I} 2$ & 11.3158 & 10.9445 & 10.2079 & 10.1829 & \\
\hline $\mathrm{I} 3$ & 9.6125 & 9.2478 & 10.3746 & 9.7857 & \\
\hline K1 & 3.1109 & 3.3539 & 3.2239 & 3.4285 & \\
\hline $\mathrm{K} 2$ & 3.7719 & 3.6481 & 3.4026 & 3.3943 & \\
\hline K3 & 3.2041 & 3.0826 & 3.4582 & 3.2619 & \\
\hline $\mathrm{R}$ & 0.6609 & 0.5655 & 0.2343 & 0.1666 & \\
\hline
\end{tabular}

Orthogonal experimental results of ginkgo bilobaleaves pigment dyed on blend yarn dyed are shown in Table.8. From Table. 8 we can see that according to the range(R) of the orthogonal experiment the sort of influence of various factors on the dyeing effect: penetration agent dosage $>$ mordant dosage $>$ dyeing $\mathrm{pH}>$ dyeing temperature, the penetration agent dosage has the maximum effect on dyeing blended yarn, this is because the penetration agent can change the surface tension of the fiber and promote the compatibility between ginkgo leaf pigment and fiber, which play a leading role. While dyeing temperature has the minimum effect on dyeing blended yarn, this suggests that best dyeing temperature of ginkgo leaf pigment should be between $60^{\circ} \mathrm{Cand} 80^{\circ} \mathrm{C}$. From the comprehensive analysis of orthogonal experiment we can determine that the optimum conditions of $1.5 \mathrm{ml}$ penetrating agent, $15 \mathrm{ml}$ mordant, $\mathrm{pH}$ value of 10 , and dyeing temperature of $60^{\circ} \mathrm{C}$.

\section{Testing of colour fastness to washing about blended yarn}

The blended yarn dyed by orthogonal experiment of 1\#, 5\#, and 8 were tested by colour fastness to washing. The testing results are shown in Table.9. From Table.9 we can see that athough three samples were dyed under different dyeing process, but their colour fastness to washing can reach up to three-level or above, especially the dyeing effect of 5\# sample and its colour to washing is the best. 
Table.9 Testing results of colour fastness to washing about blended yarn

\begin{tabular}{cccc}
\hline \multirow{2}{*}{ sample } & colour fastness/level & \multicolumn{2}{c}{ staining fastness/level } \\
\cline { 3 - 4 } & $3 \sim 4$ & cotton & wool \\
\hline 5 & $3 \sim 4$ & 3 & $3 \sim 4$ \\
8 & $3 \sim 4$ & $3 \sim 4$ & $3 \sim 4$ \\
\hline
\end{tabular}

\section{Conclusions}

During the extraction by microwave method, the sucking photometric value enchance with the increase of the ethanol dosage, but when the ethanol dosage exceed $75 \%$, there is no obvious change about the sucking photometric value of the pigment.

Taking into account dyeing costs and economic benefits, after the bestfour single-factor of $\mathrm{pH}$ value, temperature, mordant dosage, penentrating agent dosage were anayzed, we conclude that the best dying conditions of $15 \mathrm{ml}$ mordant, $1 \mathrm{ml}$ penentrating agent dosage, $\mathrm{pH}$ value of 9 , temperature of $70^{\circ} \mathrm{C}$.

From the comprehensive analysis of orthogonal experiment we can determine that the optimum conditions of $1.5 \mathrm{ml}$ penetrating agent, $15 \mathrm{ml}$ mordant, $\mathrm{pH}$ value of 10 , and dyeing temperature of $60^{\circ} \mathrm{C} .3 .3$ analysis of orthogonal experiment to determine the optimum conditions for penetrating agent $1.5 \mathrm{ml}$, mordant $15 \mathrm{ml}$ dyeing $\mathrm{pH} 10$, dyeing temperature of 60 degrees centigrade.

The colour fastness to washing and staining fastness can reach up to three-level or above.

\section{Acknowledgements}

The work is supported by industrialization promotion project of Jiangsu province, the project number is JHB2012-80.The work is also supported by visiting engineers program project in higher vocational colleges of Jiangsu Province, the project number is 2014FG107.

\section{References}

[1] Ke Guizhen, Xu Weilin, Liu Shaoguang.Dyeing of silk fabrics with natural plant dye rhizoma coptidis [J]. Textile Auxiliaries, 2007, 24(2):38-40.

[2] Sui Shijun, Cui Yongzhu. Dyeing process of cotton fabric with gingko leaf natural dye[J]. Journal of Dalian Polytechnic University, 2009, 28(6):465-468.

[3] Liu Xiangxia, Jia Yongtang, Dong Fengchun.Effects of ultrasound on dyeing behaviors of different plant dyes[J]. Textile Auxiliaries, 2010, 27(10):38-40.

[4] Yu Zhicheng, Yang Bin, Zhou Qiubao.Stability of shikonin and its performance of dyeing on wool fabrics[J].Wool Textile Journal, 2003, (2):14 16.

[5] Zhang Qipeng,Zhang Lingling,Sheng Guanzhong.Mordant dyeing of cotton with rhizoma coptidis [J].Dyeing and Finishing, 2012, (14):14 16. 